\title{
Analytical study of Pap smear reports over a period of 1 year in a tertiary care centre
}

\author{
Mehak Reyaz, Nupur Nandi*, Ritika Aggarwal
}

Department of Obstetrics and Gynecology, TMMC and RC, Moradabad, Uttar Pradesh, India

Received: 20 November 2019

Revised: 16 December 2019

Accepted: 30 December 2019

\author{
*Correspondence: \\ Dr. Nupur Nandi, \\ E-mail: nupurnandi2002@gmail.com
}

Copyright: () the author(s), publisher and licensee Medip Academy. This is an open-access article distributed under the terms of the Creative Commons Attribution Non-Commercial License, which permits unrestricted non-commercial use, distribution, and reproduction in any medium, provided the original work is properly cited.

\begin{abstract}
Background: Cervical cancer is the fourth most common cancer in women. In India and other developing countries cervical cancer is the leading cause of morbidity and mortality. Cancer cervix continues to be most common genital carcinoma in India accounting for $80 \%$ of all female genital malignancies. Pre-invase lesions can spontaneously regress to normal or remain stable for long period or progress to a higher degree of dysplasia. Cancer of cervix is preventable if diagnosed at the pre-invasive stage with regular intervals of cytological screening by Papanicolaou (Pap) smears. The aim of the study is to analyse the pap reports in terms of normal findings, infections, premalignant lesions and invasive cancers.

Methods: All women attending the outpatient department gynaecology at TMMC and RC Moradabad, Uttar Pradesh over a period of 1 year from august 2017-18 presented of obstetrics and with white discharge per vagina were screened for cervical cancer using pap smear. All the smears were reported as per the 2014 Bethesda system.

Results: Out of 1392 Pap smear reports ASCUS was reported in 27 cases (2\%), LSIL in 27 cases (2\%), HSIL in 15 cases (1\%), malignant cells in 15 cases (1\%) and normal including the infection is reported in 1308 cases (94\%).

Conclusions: Early cervical epithelial changes can be identified by a Pap smear test, which is the primary screening test for detection of precancerous cervical intraepithelial neoplasia and the early stage of invasive cervical cancer.
\end{abstract}

Keywords: Atypical typical squamous cell of undetermined significance, Cervical cancer, Cytology, High grade squamous intraepithelial lesion, Low grade squamous intraepithelial lesion, Pap smear

\section{INTRODUCTION}

Cervical cancer is the fourth most common malignancy among women in the world and is Indian women's most common genital cancer. There were 570,000 cases reported in 2018 accounting for $6.6 \%$ of all female cancer. ${ }^{1} 90 \%$ of deaths due to cervical cancer in the world occur in developing countries, with India alone accounting for $25 \%$ of the total cases of cancer cervix. ${ }^{2}$ In developing countries, cervical cancer accounts for $15 \%$ of all female malignancy.
In India, on an annual basis, about 1,32,000 cases are noted, with each year amounting to 74000 deaths in total, thus every $7^{\text {th }}$ minute cervical cancer claims the life of one women. ${ }^{3}$ It is being projected that these figures, if no action is taken are going to be doubled by the year $2020 .^{4}$ Besides mortality consequences, the morbidities associated with cervical cancer can tremendously affect the quality of women's life. In late stage cervical cancer women may present to us with irregular bleeding, back pain, pelvic pain, fatigue, loss of appetite, and weight loss..$^{5}$ 
Cervical cancer is more often preceded by a long phase of cytological changes which take 15-20 years to develop invasive cancer. So, if at earlier stages the cellular changes are diagnosed and treated, it can be prevented. ${ }^{6}$ It has been found that women in India, may present to the clinic only when they have symptoms, such as post coital bleeding, pain, foul smelling dirty discharge, and/or abnormal bleeding. ${ }^{7}$

To detect carcinoma cervix, universal awareness screening can be implemented either at premalignant stage or at early invasive stage. There are many screening procedures for timely detection of cervical cancer and its precursors, these tests may vary in their characteristics, their feasibility, and economic consideration. ${ }^{8}$ Retrospectively we have seen that using pap smears tests, the incidence of cervical carcinoma reduces by $60-90 \%$ and the death rate by $90 \%$ by detecting pre-cancerous lesions. $^{9-11}$ The sensitivity of the conventional Pap to detect high-grade lesions has a wide range from $30 \%$ to $87 \% .^{12,13}$

Therefore, we have conducted this study of analyzing Pap test reports of all married women's attending gynecological OPD after the age of 25 years.

The aim of the study is to analyze the pap reports in terms of normal findings, infections, premalignant lesions and invasive cancers.

\section{METHODS}

A 1-year hospital based prospective study with minimum of 1392 patients from August 2017-18.

\section{Inclusion criteria}

- Women with age 21-65 years who are attending gynecology OPD with complaints of pain abdomen, discharge per vagina, menstrual irregularities, postmenopausal bleeding

- Women with unhealthy cervix or cervical erosion on routine per speculum examination.

\section{Exclusion criteria}

- Women less than 21 years or $>65$ years of age.

All patients attending the department of obstetrics and gynecology, of Theerthanker Mahaveer Medical College and Research center fulfilling the inclusion criteria.

A detailed history including the demographic data, loss of appetite and weight, age at marriage, age at first intercourse, multiple sexual partners, complaints like white discharge per vagina, postmenopausal bleeding and pain in abdomen will be asked. Patients will be subjected to the following tests complete blood count, RBS, urine routine and microscopy. The smear was obtained using an Ayre spatula, rotated through 360 degree maintain contact with ectocervix. Cytobrush was inserted into the canal and was rotated through 180 degrees. Both the samples were rolled on the slide and fixed. Endocervical sample was collected using an endocervical brush. Fixation was done immediately with fixative like $95 \%$ ethyl alcohol. The prepared smear were stained with appropriate convectional pap technique and examined under light microscope. The cytological interpretation was made according to Bethesda system 2014.

\section{Statistical analysis}

Data was analyzed by SPSS version 16 and descriptive statistics were presented as frequencies and percentages.

\section{RESULTS}

In this study, we included 1392 women presenting to gynecology OPD of TMMC and RC, Moradabad, UP with various gynecological complaints and their pap smears were taken. Out of 1392 cases most of them are multiparous (>4) accounting for $42 \%$ (Table 1). Maximum number of patients, $636(46 \%)$ were in the age group of 31-40 years followed by 408 patients $(29 \%)$ in the age group of 21-30 years. There were 207 patients $(15 \%)$ in the $41-50$ years, $141(10 \%)$ in the age group of $>51$ years $($ Table 2$)$.

Table 1: Distribution of patients according to parity.

\begin{tabular}{|lll|}
\hline Parity & Number of patients (1392) & Percentage \\
\hline 1 & 198 & $14 \%$ \\
\hline 2 & 273 & $20 \%$ \\
\hline 3 & 336 & $24 \%$ \\
\hline$>4$ & 585 & $42 \%$ \\
\hline
\end{tabular}

Table 2: Distribution of patients according to age.

\begin{tabular}{|lll|}
\hline Age & Number of patients (1392) & Percentage \\
\hline $21-30$ & 408 & $29 \%$ \\
\hline $31-40$ & 636 & $46 \%$ \\
\hline $41-50$ & 207 & $15 \%$ \\
\hline$>51$ & 141 & $10 \%$ \\
\hline
\end{tabular}

Table 3: Various presenting symptoms of patients.

\begin{tabular}{|lll|}
\hline Symptoms & $\begin{array}{l}\text { Total cases } \\
(\mathbf{1 3 9 2})\end{array}$ & Percentage \\
\hline Persistent vaginal discharge & 516 & $36 \%$ \\
\hline Unhealthy cervix & 204 & $15 \%$ \\
\hline Menstrual irregularities & 249 & $18 \%$ \\
\hline Pain lower abdomen & 324 & $24 \%$ \\
\hline Postmenopausal bleeding & 99 & $7 \%$ \\
\hline
\end{tabular}

Among the 1392 women undergoing Pap smear test most common presenting complaint was persistent white discharge per vaginum $516(36 \%)$ followed by pain in lower abdomen $324(24 \%)$ patients. History of irregular menstruation was present in $249(18 \%)$ cases, unhealthy 
cervix in $204(15 \%)$ cases and postmenopausal bleeding $99(7 \%)$ patients (Table 3$)$.

Out of 1392 cases normal including the infection is reported in 1308 cases (94\%), followed by ASCUS in 27 cases (2\%), LSIL in 27 patients (2\%), HSIL in 15 cases (1\%) and malignant cells in 15 cases (1\%) (Table 4). Therefore, it is recommended that women should have at least 1 Pap before the age of 45 years. The incidence of cervical cancer is quite high because prevention programs are either non-existent or poorly implemented. The Pap smear test used as a screening tool to identify cervical cancer is an effective way to reduce cervical cancer from emerging, but public awareness of the Pap smear test is very low.

Table 4: Pap smear analysis.

\begin{tabular}{|lll|}
\hline PAP Smear & $\begin{array}{l}\text { Total cases } \\
(\mathbf{1 3 9 2})\end{array}$ & Percentage \\
\hline Normal (including infection) & 1308 & $94 \%$ \\
\hline ASCUS & 27 & $2 \%$ \\
\hline LSIL & 27 & $2 \%$ \\
\hline HSIL & 15 & $1 \%$ \\
\hline Malignant cells & 15 & $1 \%$ \\
\hline
\end{tabular}

Table 5: Pap smear interpretation by Bethesda system.

\begin{tabular}{|lllll|l|}
\hline AGE $($ years $)$ & $\begin{array}{l}\text { Normal including } \\
\text { infection 94\% }(\mathbf{n}=1308)\end{array}$ & $\begin{array}{l}\text { ASCUS 2\% } \\
(\mathbf{n}=\mathbf{2 7})\end{array}$ & $\begin{array}{l}\text { LSIL 2\% } \\
(\mathbf{n}=\mathbf{2 7})\end{array}$ & $\begin{array}{l}\text { HSIL 1\% } \\
(\mathbf{n}=\mathbf{1 5})\end{array}$ & $\begin{array}{l}\text { Malignancy } \\
\mathbf{1 \%}(\mathbf{n}=\mathbf{1 5})\end{array}$ \\
\hline $21-30(29 \%)(\mathrm{n}=408)$ & 402 & 12 & 6 & 15 & 9 \\
\hline $31-40(46 \%)(\mathrm{n}=636)$ & 609 & 9 & 6 & 9 & 6 \\
\hline $41-50(15 \%)(\mathrm{n}=207)$ & 174 & 6 & & 6 & 6 \\
\hline$>50(10 \%)(\mathrm{n}=141)$ & 123 & 14 & & 6 \\
\hline
\end{tabular}

Table 6: Correlation of Pap finding with symptoms.

\begin{tabular}{|c|c|c|c|c|c|c|c|}
\hline Symptoms & & $\begin{array}{l}\text { Normal including } \\
\text { infection }\end{array}$ & ASCUS & LSIL & HSIL & Malignancy & Total \\
\hline \multirow{5}{*}{$\begin{array}{l}\text { Menstrual } \\
\text { irregularities }\end{array}$} & Count & 246 & 3 & 0 & 0 & 0 & 249 \\
\hline & Expected count & 76.8 & 1.6 & 1.6 & 0.9 & 0.9 & 83.0 \\
\hline & $\%$ within symptoms & $98.8 \%$ & $1.2 \%$ & $0 \%$ & $0 \%$ & $0 \%$ & $100.0 \%$ \\
\hline & $\%$ within pap & $18.8 \%$ & $11.1 \%$ & $0 \%$ & $0 \%$ & $0 \%$ & $17.6 \%$ \\
\hline & $\%$ of total & $17.4 \%$ & $0.2 \%$ & $0 \%$ & $0 \%$ & $0 \%$ & $17.6 \%$ \\
\hline \multirow{5}{*}{ PMB } & Count & 75 & 6 & 9 & 6 & 3 & 99 \\
\hline & Expected count & 30.5 & 0.6 & 0.6 & 0.4 & 0.4 & 33.0 \\
\hline & $\%$ within symptoms & $75.8 \%$ & $6.1 \%$ & $9.1 \%$ & $6.1 \%$ & $3.0 \%$ & $100.0 \%$ \\
\hline & $\%$ within pap & $5.7 \%$ & $22.2 \%$ & $33.3 \%$ & $40.0 \%$ & $20.0 \%$ & $7.0 \%$ \\
\hline & $\%$ of total & $5.3 \%$ & $0.4 \%$ & $0.6 \%$ & $0.4 \%$ & $0.2 \%$ & $7.0 \%$ \\
\hline \multirow{5}{*}{$\begin{array}{l}\text { Unhealthy } \\
\text { cervix }\end{array}$} & Count & 159 & 9 & 15 & 9 & 12 & 204 \\
\hline & Expected count & 62.9 & 1.3 & 1.3 & 0.7 & 0.7 & 68.0 \\
\hline & $\%$ within symptoms & $77.9 \%$ & $4.4 \%$ & $7.4 \%$ & $4.4 \%$ & $5.9 \%$ & $100.0 \%$ \\
\hline & $\%$ within pap & $12.2 \%$ & $33.3 \%$ & $55.6 \%$ & $60.0 \%$ & $80.0 \%$ & $14.4 \%$ \\
\hline & $\%$ of total & $11.3 \%$ & $0.6 \%$ & $1.1 \%$ & $.6 \%$ & $.8 \%$ & $14.4 \%$ \\
\hline \multirow{5}{*}{$\begin{array}{l}\text { Pain } \\
\text { abdomen }\end{array}$} & Count & 321 & 0 & 3 & 0 & 0 & 324 \\
\hline & Expected count & 100.0 & 2.1 & 2.1 & 1.1 & 1.1 & 108.0 \\
\hline & $\%$ within symptoms & $99.1 \%$ & $0 \%$ & $0.9 \%$ & $0 \%$ & $0 \%$ & $100.0 \%$ \\
\hline & $\%$ within pap & $24.5 \%$ & $0 \%$ & $11.1 \%$ & $0 \%$ & $0 \%$ & $22.9 \%$ \\
\hline & $\%$ of total & $22.7 \%$ & $0 \%$ & $.2 \%$ & $0 \%$ & $0 \%$ & $22.9 \%$ \\
\hline \multirow{5}{*}{$\begin{array}{l}\text { Vaginal } \\
\text { discharge }\end{array}$} & Count & 507 & 9 & 0 & 0 & 0 & 516 \\
\hline & Expected count & 159.2 & 3.3 & 3.3 & 1.8 & 1.8 & 172.0 \\
\hline & $\%$ within symptoms & $98.3 \%$ & $1.7 \%$ & $0 \%$ & $0 \%$ & $0 \%$ & $100.0 \%$ \\
\hline & $\%$ within pap & $38.8 \%$ & $33.3 \%$ & $0 \%$ & $0 \%$ & $0 \%$ & $36.5 \%$ \\
\hline & $\%$ of total & $35.9 \%$ & $.6 \%$ & $0 \%$ & $0 \%$ & $0 \%$ & $36.5 \%$ \\
\hline
\end{tabular}

Among 1308 cases of normal including infection reports, 609 cases were found in 31-40 age group followed by 402 in 21-30-year age group, 174 in 41-50 years and 123 in $>50$ years of age. Among 27 cases of ASCUS, 12 cases were found in 31-40 years of age whereas 9 cases in 4150 -year age group and 6 in $>50$ years of age (Table 5). 
LSIL was found in 27 cases out of which 15 cases were reported in 31-40 years 6 in 21-30 years and 41-50 years each. HSIL and Malignancy were found to be higher ( 9 cases) in age group of 41-50 years each group.

Out of 1392 cases, unhealthy cervix was found in 204 cases among which 9 cases had ASCUS and HSIL each, 15 had LSIL and 12 had Malignancy rest 159 cases were normal including infection (Table 6).

Among 99 cases of PMB, 3 cases were malignant, 9 cases had LSIL, 6 had ASCUS and HSIL each. Among 516 cases of persistent white discharge maximum number of cases i.e., 507 had normal including infection (Table 6).

\section{DISCUSSION}

Due to changes in the lifestyle and changes in demographic profile in developing countries, noncommunicable diseases are on the increase as an important health problem that requires effective control program before they become involved in their epidemic spread. According to National Cancer Registry Program of India, most common cancer reported is cervical cancer and breast cancer. Specific age groups must be subjected to universal screening in order to detect precancerous conditions, before they take their invasive forms.

In this report, 1392 Pap smears were taken from women attending to Gynecology OPD of TMMC and RC Moradabad, with different Gynecological complaints. In our study, mostly women belong to age group of 31-40 years $(46 \%)$. The total number of women in Bamanikar et al, was between 31 and 40 years of age (32.68 percent). ${ }^{14}$ In Patel et al, majority of cases $36.1 \%$ were in the age group of 31-40 years (Table 2). ${ }^{15}$

In present study, the most common presenting symptom was white discharge per vaginum (36\%). In study conducted by Chaudhary et al, Gupta et al, most common symptom was discharge per vagina accounting for $40 \%$ of cases. In our study, $2^{\text {nd }}$ most common symptom was pain abdomen $24 \% .{ }^{16,17}$ In study conducted by Patel et al, $17.3 \%$ patients presented with pain in abdomen. 3rd common symptom was menstrual irregularities $18 \%$, as reported in Gupta et al, irregular bleeding was present in $25 \%$ of the patients. ${ }^{15,17}$

Other symptoms were unhealthy cervix $15 \%$ and postmenopausal bleeding $7 \%$. In this study the high prevalence of abnormalities are due to parity, low socioeconomical status, illiteracy, poor hygiene (Table 3).

In this study, normal including infection were reported in 94\% of cases, whereas in Bamanikar et al, $71.96 \%$ cases were reported and in Bal MS et at, 57.5\% cases were reported. ${ }^{14,18}$ A few studies reported that women with persistent inflammation should be appropriately treated; otherwise, the chance of development of cervical intraepithelial lesions increases. A repeat Pap smear should be taken after proper antibiotic treatment (Table $4)$.

Smears with ASCUS (Atypical squamous cells of undetermined significance) as their findings were $2 \%$ in present study, Laksmi et al. ${ }^{19} 2.5 \%$ reported similar results in the study. In study conducted by Bamanikar et al, 2.3\% reports showed ASCUS. ${ }^{14}$ The high prevalence of cytological abnormalities observed in Indian studies might be due to cultural differences, age of individual, incidence of related infections, awareness about screening and presence or absence of screening programme in different parts of country.

Cervical cancer commonly develops in women between 40 to 50 years and its precursor lesion usually between 5 to 10 years. Smears with LSIL (low intraepithelial squamous lesions) are documented to be $2 \%$. In Bamanikar et al, $1.9 \%$ reports gave LSIL while in Bal MS et al 0.1\% LSIL were reported. ${ }^{14,18}$ In this research, records of HSIL (high-grade intraepithelial squamous lesion) are $1 \%$. HSIL reports were 6 percent in Lakshmi et al, $0.3 \%$ in Bamanikar et al, $0.1 \%$ in Bal MS et al. ${ }^{14,18,19}$

Squamous cell carcinoma was found to be $1 \%$ similar in our sample findings in Lakshmi et al, $1 \%$ study. ${ }^{19}$ Squamous cell carcinoma was documented in the study conducted by Bamanikar et al, $14.5 \%$ and $0.7 \%$ in the study conducted by $\mathrm{Bal}$ MS et al, records showing squamous cell carcinoma. ${ }^{18}$

ASCUS was mostly i.e., 609 cases were seen in the age group of 31-40 years in this study, similar results were found in the study of Patel MM et al. ${ }^{20}$ Followed by 402 in 21-30-year age group, 174 in 41-50 years and 123 in > 50 years of age. LSIL was found in 27 cases out of which 15 cases were reported in 31-40 years 6 in 21-30 years and $41-50$ years each.

To prevent cervical malignancies, Pap smear examination is advocated in all women of 21 years of age. ${ }^{21}$ As Pap smear examination is most efficient of all method it is regarded as gold standard screening method. ${ }^{22}$ In this study HSIL and Malignancy was found in higher age group above 40 years as in Tejeswini et al. ${ }^{23}$ Women aged 45 years or above harbor the bulk of premalignant and malignant lesion.

Mandakini et al, showed predominantly inflammatory and benign lesions while premalignant and malignant lesions accounted to $<10 \%$ (Table 5). ${ }^{20}$

Most common symptom in this study was white discharge per vagina accounting for $36 \%$. Out of 516 cases of white discharge per vagina, 507 had normal report including infection and 9 were ASCUS. Unhealthy cervix was found in 204 cases among which 9 cases had ASCUS and HSIL each, 15 had LSIL and 12 had Malignancy rest 159 cases were normal including 
infection. Among 99 cases of PMB, 3 cases were malignant, 9 cases had LSIL, 6 had ASCUS and HSIL each. Among 516 cases of persistent white discharge maximum number of cases i.e., 507 had normal including infection. Out of 249 cases of menstrual irregularities ASCUS was found in 3 cases and rest 246 were normal including infection (Table 6).

Screening has to be based on an adequate health infrastructure. There must be a defined target population, and means to identify, invite, screen and follow-up that population. The women in this population will have to be educated about screening for cervical cancer, and the health professionals who serve them may need education and retraining.

The major advantages of cytology screening are the considerable experience accrued worldwide in its use, and that it is so far the only established screening test for cervical cancer precursors that has been shown to reduce the incidence and mortality of the disease.

\section{CONCLUSION}

Pap smear tests are less costly (easily affordable by the patient). This procedure does not need expert person or specialists for collection of smears.

Early detection helps in immediate treatment at early stage and thereby reducing the mortality and morbidity of cancer cervix. Sensitivity of pap as screening test can be increased with universal screening of all women attending gynecological OPD.

Funding: No funding sources

Conflict of interest: None declared

Ethical approval: The study was approved by the Institutional Ethics Committee

\section{REFERENCES}

1. Cecilia NC, Rosliza AM, Suriani I. Global burden of cervical cancer; a literature review. Int $\mathrm{J}$ Public Health Clin Sci. 2017;4(2):10-8.

2. WHO Cervical Cancer statistics worldwide. 2018. CA. A Cancer J Clin. 2018;1-31.

3. Ferlay J, Soerjomataram I, Dikshit R, Eser S, Mathers C, Rebelo M, et al. Cancer incidence and mortality worldwide: Sources, methods and major patterns in GLOBOCAN 2012. Int $\mathbf{J}$ Cancer. 2015;136:E359-86.

4. Parkin FJ, Pisani P. Cancer Incidence, mortality and prevalence worldwide: Sources, methods and major patterns in GLOBOLAN 2002. IARC. 2005;55(2):74-108.

5. Duraisamy K, Jaganathan KS, Bose JC. Methods of detecting cervical cancer. Adv Biol Res. 2011;5(4):226-32.
6. Jones SC, Johnson K. Women's awareness of cancer symptoms: a review of the literature. Woman's Health (Lond). 2012;8:579-91.

7. Franco EL, Duarte Franco E, Ferenczy A. Cervical cancer: epidemiology, prevention and role of human papillomavirus infection. CMAJ. 2001;164(7):101725.

8. Patel MM, Pandya AN, Modi J. Cervical Pap smear study and its utility in cancer screening, to specify the strategy for cervical cancer control. National $\mathbf{J}$ Comm Med. 2011;2:49-51.

9. Behtash N, Mehrdad N. Cervical Cancer: Screening and Prevention. Asian Pac J Cancer Prev. 2006;7(4):683-6.

10. Fahey MT, Irwig L, Macaskill P. Meta-analysis of Pap test accuracy. Am J Epidemiol. 1995;141(7):680-9.

11. Mitchell MF, Schottenfeld D, Tortolero-Luna G, Cantor SB, Richards-Kortum R. Colposcopy for the diagnosis of Squamous intraepithelial lesion: A Meta-analysis. Obstet Gynecol. 1998;91(4):626-31.

12. Nanda K, McCrory DC, Myers ER, Bastian LA, Hasselblad V, Hickey JD, et al. Accuracy of Pap test in screening for or follow up of cervical cytologic abnormalities: a systematic review. Ann Intern Med. 2000:132(10):810-9.

13. American College of Gynecologists. ACOG Practice Bulletin No. 99: management of abnormal cervical cytology and histology. Obstet Gynecol. 2008;112(6):1419-44.

14. Bamanikar SA, Baravkar DS, Chandanwale SS, Dapkekar P. Study of cervical Pap smears in a Tertiary Hospital. Indian Med Gazette. 2014:250-4.

15. Patel CB, Shah PC, Bhagat VM. A role of cervical Pap smear as a screening tool in diagnosis of lesions of cervix-a one-year study. Int J Med Sci Public Health. 2016;5(9):1841-6.

16. Chaudhary RD, Inamdar SA, Hari Haran C. Correlation of diagnostic efficacy of unhealthy cervix by cytology, colposcopy and histopathology in women of rural areas. Int Reprod Contracept Obstet Gynecol. 2014;3(1):213-8.

17. Gupta R, Gupta SG, Mishra KB. Pattern of Pap smear cytology and its histopathological correlation at a tertiary care center. Rec Adv Path Lab Med. 2016;2(2):13-9.

18. Bal MS, Goyal R, Kumar A, Suri AK, Mohi MK. Detection of abnormal cervical cytology in papnicolaou smears. J Cytol. 2012;29:45-7.

19. Lakshmi PV, Sree Gouri SR. Study and analysis of two hundred cervical PAP smears. Int J Contem Med Res. 2016;3(9):2787-9.

20. Mandakni MP, Amrish NP, Jigna M. Cervical pap smear study and its utility in cancer screening, to specify the strategy for cervical cancer control. National J Comm Med. 2011;2(1):50.

21. ACOG Practice Bulletin. Clinical management guidelines for obstetrician-gynaecologists; 2009. 
22. Cheryl LR, Clair WM, Kevin R. Prevention of cervical cancer. Crit Rev Oncol/Haematol. 2000;33:169-85.

23. Tejeswini V, Premalath P. Pap smear examinationits utility in various cervical lesions. Indian J Pathol Oncol. 2016;3(2):242-6.
Cite this article as: Reyaz M, Nandi N, Aggarwal R. Analytical study of Pap smear reports over a period of 1 year in a tertiary care centre. Int J Reprod Contracept Obstet Gynecol 2020;9:624-9. 